\title{
Cuando la literatura quebequense vuela en Iberia: mitos y realidades de la traducción al español
}

\author{
María Sierra Córdoba Serrano*
}

\section{RESUMEN}

La autora de este artículo pone a prueba el supuesto según el cual, en el caso de la narrativa quebequense traducida al español, España actúa como puerta de entrada al continente americano. Para ello, partiendo de una sociología de corte bourdieusiano, analiza la circulación en el espacio hispánico de traducciones de narrativa quebequense publicadas en España entre 1990 y 2012, y distribuidas o coeditadas en suelo americano. La autora concluye que, especialmente en el caso de los conglomerados editoriales internacionales, España actúa como barrera que impide una segunda vida a estas traducciones en el continente americano.

Palabras clave: literatura quebequense, intercambios literarios transatlánticos, sociología de la edición internacional, Pierre Bourdieu, estudios de traducción.

\section{ABSTRACT}

This article's author puts to the test the supposition that in Quebecois narrative translated into Spanish, Spain acts as the entryway to the Western Hemisphere. Based on Bourdieusian sociology, she analyzes the circulation in the Spanish-speaking world of Quebecois narrative published in Spain between 1990 and 2012 and distributed or co-published in the Americas. The author concludes that, particularly in the case of international publishing conglomerates, Spain acts as a barrier that impedes a second life for these translations in the hemisphere.

Key words: Quebecois literature, transatlantic literary exchanges, sociology of international publishing, Pierre Bourdieu, translation studies.

* Profesora asociada, Monterey Institute of International Studies, Graduate School of Translation, Interpretation \& Language Education, <mcordobaserrano@miis.edu>. 
En 2007, aparecía en el periódico quebequense Le Devoir y en el francés Le Monde una especie de manifiesto que clamaba que "Le centre n'est plus le centre" [el centro ya no es el centro]. Francia había dejado de ser el centro simbólico en torno al cual giraba la literatura quebequense y los autores de la Belle Province no necesitaban desde hacía tiempo el "imprimatur" francés para "existir" en la república mundial de las Letras (Casanova, 1999). En principio, este manifiesto parecía dar por concluido un proceso de ruptura con respecto al campo literario francés que, en el caso de la literatura quebequense, venía gestándose desde los años setenta.

No obstante, partiendo de la hipótesis según la cual la traducción puede ser una variable ineludible a la hora de "medir" la dependencia literaria de las literaturas periféricas (una especie de prueba de fuego para determinar si quedan resquicios de dicha dependencia), quisimos precisamente poner a prueba la independencia de la literatura quebequense desde el prisma de la traducción (Córdoba Serrano, 2010; 2013). En concreto, analizamos el caso de la narrativa quebequense traducida en España entre 1979 y 2004. ${ }^{1} \mathrm{Al}$ examinar la circulación internacional de dicha literatura en el marco del trasvase mencionado, constatamos una especie de triángulo QuebecFrancia-España: salvo en el caso de la literatura infantil y juvenil, vimos que la literatura quebequense "pasa" casi obligatoriamente por Francia antes de partir rumbo a España, es decir, los editores españoles suelen traducir autores quebequenses siempre y cuando sus vecinos franceses hayan dado antes el visto bueno de una forma $u$ otra (ya sea publicando ellos mismos a esos autores en Francia o editándolos simultáneamente con algún editor quebequense, esto es, coeditándolos), todo lo cual pone de manifiesto los distintos mecanismos de los que aún se sirve el centro simbólico francés para ejercer su influencia.

Ampliando ahora nuestro espacio observado y centrándonos en el caso de la circulación de la narrativa quebequense traducida no sólo en España, sino en el mundo hispánico en general, quedan por examinar otros centros y otras influencias. En concreto, en este artículo nos ocuparemos del centro español: ¿es España una puerta de entrada de la narrativa quebequense a América Latina y a Estados Unidos, como parecen creer los editores quebequenses y canadienses, así como sus gobiernos respectivos, a juzgar por las estrategias de internacionalización y de exportación de la literatura que emplean?, ¿hasta qué punto la narrativa quebequense traducida al español viaja en Iberia para llegar al continente americano y qué consecuencias conlleva volar en Iberia vía Madrid o Barcelona en lugar de tomar un vuelo directo a la Ciudad de México, Buenos Aires o Bogotá?

\footnotetext{
${ }^{1}$ Nos limitamos en aquel entonces y seguimos haciéndolo en este artículo a la narrativa quebequense escrita en francés.
} 
Éstas son algunas de las preguntas que trataremos de dilucidar en este artículo. Dado el espacio limitado del que disponemos, nos centraremos en la narrativa para adultos. Además de la narrativa infantil y juvenil, descartaremos otros géneros como la poesía y el teatro, ya que éstos presentan circuitos y dinámicas que les son propios y que, por lo tanto, merecen ser analizados por separado.

\section{Geopolítica del MUNDO EDITORIAL DE haBLA HISPANA: APUNTES GENERALES}

En la introducción de la guía Selling Canadian Books in Spain: A Guide for Canadian Publishers, que la Asociación para la Exportación del Libro Canadiense encargó a Juliet King Daum (2005: 2), se explica que “The Spanish market is an appealing one for Canadian publishers because it provides access to over 40 million people living in Spain, and it serves as the gateway to all of Latin America" (Daum, 2005: 2) y a Estados Unidos, de ahí que haya que verlo no como un mercado nacional, sino internacional. Prosigue explicando que "Spanish publishers decide what people will read in Spain, and they also largely determine what titles will be available in the Spanishspeaking world, in Argentina, Colombia, Venezuela, Mexico, and right up to the United States with its growing population". Y, desde luego, las ideas expuestas en esta guía para animar a los editores canadienses a lanzarse al mercado de lengua española no contradicen en lo más mínimo otros datos sobre el espacio iberoamericano del libro que encontramos en los informes publicados por el Centro Regional para el Fomento del Libro en América Latina y el Caribe (Cerlalc). Así, en su informe de 2006, se indica que diecisiete de las treinta y tres principales editoriales latinoamericanas son originarias de España (Cerlalc, 2006: 96). En un informe más reciente (Cerlalc, 2012: 15), se presentan asimismo datos en materia de producción de títulos en Iberoamérica, según los cuales el 55 por ciento de los títulos que se publican en dicho espacio se registran en América Latina, de los cuales el 22 por ciento provienen de Brasil, es decir, que sólo el 33 por ciento ${ }^{2}$ de los títulos publicados en español se editan en América Latina frente al 39 por ciento de España. ${ }^{3}$ Conviene destacar que algunos de estos títulos considerados como latinoamericanos (esto es, que tienen ISBN latinoamericano) son en realidad títulos que se han editado en España, pero que fueron impresos en América Latina por filiales locales latinoamericanas de grupos

\footnotetext{
${ }^{2}$ Los países más representados son Argentina, con un 10 por ciento del total de títulos producidos en América Latina; México, con un 8 por ciento, y Colombia, con un 5 por ciento (Cerlalc, 2012: 15).

${ }^{3}$ El porcentaje restante corresponde a títulos editados e impresos en Portugal.
} 
editoriales españoles. Cabe asimismo puntualizar que el porcentaje de títulos producidos en Hispanoamérica incluye no sólo títulos (originales y traducciones) de editoriales comerciales, sino también de editoriales universitarias, editores fundaciones (es decir, ciertas organizaciones no gubernamentales -ONG-, organismos del sector público, etc.), así como autopublicaciones o ediciones de autor. De hecho, si nos limitáramos a las editoriales comerciales, el panorama en Hispanoamérica sería aún más desolador, y los porcentajes de la producción local, mucho más bajos.

En cuanto a facturación se refiere, en Argentina y México juntos, los gigantes de la región, se obtienen ingresos por ventas de libros que representan el 40 por ciento de lo que se genera en España (Lionetti, 2012). O como lo expresa Fernández Moya (2009: 75), “pese a que España supone apenas el 10 por ciento de los hispanohablantes del mundo, el 50-60 por ciento de la facturación mundial en español se realiza en editoriales situadas en España, porcentaje que aumentaría si incluyéramos la edición de las filiales locales de empresas españolas en América Latina". El monopolio de los grandes grupos editoriales españoles en el mapa de la edición iberoamericana, así como las asimetrías que caracterizan este espacio, es algo innegable. Como se pone de relieve en la famosa revista Publishing Perspectives: "While publishers in Brazil own their own copyrights, the main Spanish-language Latin American copyrights are held by publishers sitting in Madrid or Barcelona. Latin American writers of high commercial value publish with Spanish houses or have Spanish agents. What's left outside Spain's influence? The titles of regional interest, long-form journalism, current affairs" (Lionetti, 2012).

Lo mismo se podría decir del mercado de la traducción: las decisiones más cruciales se toman desde España y afectan al resto del mundo hispanohablante. Así pues, cuando las multinacionales españolas adquieren derechos de traducción al español, se trata de derechos mundiales, es decir, de derechos para todos los territorios de habla hispana y no sólo para España, lo cual deja poco margen de maniobra a los pequeños sellos locales latinoamericanos. En una entrevista reciente a Elena Ramírez, directora editorial del sello Seix Barral, del Grupo Planeta, destacaba que, de hecho, su editorial siempre intenta comprar los derechos de traducción mundiales en español de un autor dado y "si no -añade-, no los compramos. [...] Si cualquier territorio de habla hispana no está libre, no me interesa, a menos que en un país dado lo publique una editorial universitaria sin apenas distribución" (Ramírez, 2013). Puntualiza asimismo que en el 99 por ciento de los casos sus traducciones se publican tanto en España como en América Latina (una afirmación que, como veremos más adelante, es cuestionable a partir de los datos empíricos obtenidos). José López Jara, director editorial de Minotauro, sello también perteneciente al Grupo Planeta, señala que, especialmente en el momento actual de crisis en el que se en- 
cuentra España y dada la disminución de las ventas de libros en la Península Ibérica, "hay proyectos [de traducción] que sólo los ha[cen] si hay potencial en América Latina" (López Jara, 2013). No obstante, la editora de mesa ${ }^{4}$ de otro sello de este mismo grupo (cuyo nombre no podemos desvelar por razones de confidencialidad), en un tono más personal, deja escapar que "para conseguir los derechos de un autor dado, en Planeta lo venden siempre como que conseguirá la presencia del libro en América Latina. Éste es el argumento que convence a las agencias literarias y autores para que les vendan los derechos" (2013; el subrayado es mío). ¿Quiere esto decir que, en ocasiones, tengan o no la intención de distribuir o coeditar una traducción española en América Latina o en Estados Unidos, lo importante es fingir que así será para convencer al autor del original o a su agente de que les ceda los derechos mundiales en lengua española?

Esto significaría que los editores que pueden comprar derechos mundiales y tienen los recursos necesarios para distribuir o coeditar una traducción en América Latina y Estados Unidos no siempre lo hacen. Puede que tengan la intención de hacerlo en principio, pero, en la práctica, saben que, con ciertos autores menos comerciales, hay pocas probabilidades de que el título tenga una segunda vida después de España (especialmente dados los criterios de rentabilidad en los que suelen basar sus decisiones, como veremos en las líneas que siguen).

En ese caso, cabría proponer una nueva hipótesis (o quiza se trate más bien de un cambio de perspectiva) según la cual, para los autores de literaturas periféricas publicados por grandes grupos editoriales españoles, ${ }^{5}$ España no actúa como puerta de entrada al mercado latinoamericano, sino más bien como barrera de entrada.

\section{¿HAY VIDA DESPUÉS DE ESPAÑA? \\ LA CIRCULACIÓN INTERNACIONAL DE LA NARRATIVA QUEBEQUENSE TRADUCIDA EN EL MUNDO HISPANOHABLANTE}

En lugar de limitarnos al discurso que sostienen los editores u otros agentes institucionales sobre sus prácticas editoriales en materia de proyección internacional de sus traducciones, partiremos de un corpus concreto que hemos estudiado en profundidad anteriormente y cuyos criterios metodológicos de delimitación ya se han defi-

\footnotetext{
${ }^{4}$ Es la persona que colabora más directamente con el traductor para mejorar el texto traducido. Podríamos decir que es una especie de corrector de plantilla de la editorial.

${ }^{5}$ Los resultados serían probablemente distintos para autores canadienses más (re)conocidos como Margaret Atwood, Carol Shields, Michael Ondaatje, Yann Martel, entre otros. Sin embargo, hasta el momento, tampoco se ha demostrado empíricamente que sea así.
} 
nido en publicaciones anteriores (Córdoba Serrano, 2013: 9-12): me refiero a la narrativa quebequense traducida al español en España entre 1975 y 2004; sin embargo, esta vez trascenderemos el espacio editorial español para transportarnos al otro lado del Atlántico y, además, nos centraremos concretamente en el periodo comprendido entre 1990 y $2012 .^{6}$

Antes de adentrarnos en nuestra tarea, es conveniente aclarar varios conceptos que utilizaremos en las líneas que siguen, que tienen que ver con las estrategias que utilizan los grupos editoriales españoles y los editores independientes para estar presentes en el continente americano: nos referimos en concreto a los conceptos de distribución y de coedición.

Como indica Fernández Moya en sus trabajos sobre la internacionalización del sector editorial español (2008; 2009 y 2012), aunque bien es cierto que la visibilidad de los grupos editoriales en América Latina es especialmente notoria desde el último cuarto del siglo $\mathrm{xx}$, su presencia data de principios de siglo, y su internacionalización debe entenderse como un proceso gradual que llega hasta nuestros días. ${ }^{7}$ En la actualidad, los editores españoles participan en el mercado americano a través de dos estrategias fundamentales, en función de su volumen de ventas en cada país y de su capacidad financiera (Fernández Moya, 2009: 72-73): el primer modelo estaría representado por las editoriales españolas que recurren a algún tipo de acuerdo de representación con distribuidoras latinoamericanas (o en algunas ocasiones con otras editoriales latinoamericanas que les sirven de distribuidoras). A los costos de transporte, los impuestos arancelarios y otras barreras a la importación que imponen algunos gobiernos, se suma el porcentaje elevado que las distribuidoras se quedan de las ventas de los ejemplares distribuidos y el hecho de que el distribuidor no promueve en sí los títulos que distribuye. En resumidas cuentas, se trata de una estrategia cara y generalmente poco efectiva. Eso explica por qué los grupos editoriales han acudido a una segunda estrategia: la implantación de una filial en suelo americano. En general en su proceso de implantación, como nos indica Fernández Moya, estas filiales suelen ser comerciales en un principio (es decir, la filial comercial se limita a

\footnotetext{
${ }^{6}$ Hemos seleccionado los noventa porque, según lo observado en estudios anteriores (Córdoba Serrano, 2013), es en esa década cuando verdaderamente se empieza a traducir narrativa quebequense en España (además de que queríamos títulos que no fueran tan antiguos como para haber desaparecido de los catálogos digitales de las librerías consultadas), y 2012 porque hemos querido obtener datos actuales, pero al mismo tiempo, completos (y el último año completo del que disponemos de datos es el 2012). Hemos seleccionado años recientes, además, para asegurarnos de que los títulos analizados (aunque algunos de ellos se hubieran agotado) estuvieran todavía recogidos en los catálogos digitales de las librerías que comprenden nuestra muestra y que presentaremos a continuación.

${ }^{7}$ Para un recorrido histórico de este proceso en sus distintas fases, véanse Fernández Moya 2008, 2009 y 2012, quien distingue tres fases: de 1900 a 1936, de 1939 a 1975 y de 1975 hasta nuestros días (Fernández Moya, 2009: 66).
} 
distribuir en América Latina libros editados en España), para paulatinamente convertirse en filiales productivas, es decir, sellos locales que coeditan títulos con su casa matriz española o que editan autores nacionales específicamente para su mercado local. ${ }^{8}$ En el marco de esta segunda estrategia, cabe destacar que la coedición abarca un espectro muy amplio que puede ir desde la mera impresión de una traducción española en México por un sello "local" mexicano, sello que a veces simplemente cambia la portada y promueve la traducción como suya (y que a su vez lleva un ISBN mexicano), hasta casos en los que la editorial mexicana no se limita a imprimir el título en México, sino que lo edita y adecua a su público local. Es, por ejemplo, la estrategia que suele adoptar Minotauro para algunas de sus traducciones, según nos explicó su director editorial José López Jara (2013):

Cuando un libro realmente interesa mucho en un país de América Latina (estoy pensando especialmente en México, Argentina, Chile y Colombia), lo que suele pasar también -por razones que no tienen ya que ver con la pura edición, sino con el coste de producción de los libros- es que estos países hacen su edición: nosotros les mandamos el documento digital y ellos lo revisan antes de hacer su edición, con lo cual hacen la corrección para adecuarlo al español de este país.

López Jara da el ejemplo de la literatura de género, la literatura de terror, para ser más exactos, y menciona el caso concreto de la serie The Walking Dead.

En los informes sobre el sector editorial (Icex España Exportación e Inversiones, 2012: 30), se insiste en que los grandes grupos editoriales españoles con mayor presencia en América Latina siguen exportando libros desde España por medio de la

\footnotetext{
${ }^{8}$ Además de editar autores y temas nacionales, como bien apunta Fernández Moya (2009: 74), hay que destacar que "la estrategia de americanización y la concentración del sector llevaron, en los años ochenta y noventa, a la absorción por parte de las empresas españolas de editoriales históricas autóctonas, que pasaron a ser filiales de la casa matriz española". Es, por ejemplo, lo que ocurrió con una editorial tan mexicana como Diana, que en 2006 fue absorbida por el Grupo Planeta, o en 1986 pasó algo similar con la editorial Joaquín Mortiz (esta última, aunque fue fundada por un exiliado español, es considerada un pilar en la promoción de autores mexicanos). Todo esto hace que la frontera entre lo nacional y lo extranjero-español esté muy difuminada, que es lo que realmente pretenden estas multinacionales: hacer creer al lector mexicano que está consumiendo un producto local. Y a veces es así, pero en muchas otras ocasiones, sobre todo en el caso de las traducciones, las decisiones se toman en Madrid o en Barcelona. Y aunque las medidas proteccionistas de algunos gobiernos deberían ayudar a fomentar la edición local, vemos que, en la práctica, esta frontera poco definida entre lo local y lo extranjero impide que algunas medidas sean efectivas. Por ejemplo, Icex España Exportación e Inversiones (2012: 28) ilustra este aspecto con un ejemplo muy interesante sobre México:
}

[...] el Estado es el principal comprador de libros infantiles y juveniles, en concreto, la Comisión Nacional de Libros de Texto Gratuitos [Conaliteg], que es la encargada de adquirir libros para el programa Bibliotecas de Aula. Para poder optar a este programa, es requisito indispensable que los libros sean editados en México por editoriales mexicanas, lo cual supone una barrera insalvable, en apariencia, para las editoriales extranjeras. En la práctica no tiene por qué ser así, ya que los productos de las editoriales extrajeras implantadas en México se consideran producto mexicano. 
distribución, pero que, sobre todo, editan en los países americanos gran parte de los libros que distribuyen. Por ejemplo, Planeta calcula que en el 2004 el 70 por ciento de los títulos que se distribuyeron en México fueron editados en este país (el 30 por ciento restante fueron importados de España), y, según Océano, alrededor del 60 por ciento de los títulos que distribuye en México son también editados en este país; sin embargo, es importante interpretar estos datos con precaución porque, como mencionamos en el apartado anterior, un título puede que sólo se considere mexicano y tenga ISBN mexicano (referencia principal a la hora de recopilar datos para estos informes) porque se imprimió en México, aunque se haya editado en España. En definitiva, los productos de las editoriales extranjeras implantadas en México se consideran producto mexicano (Icex España Exportación e Inversiones, 2012: 28), lo cual puede llevar a un retrato mucho más halagüeño de la producción local de lo que lo es en realidad y ocultar ciertas asimetrías e influencias del centro español. Y si algo no se detecta y se disfraza, es muy difícil poder cambiarlo, especialmente en lo que respecta al mercado de la traducción, esta insistencia en la importancia de la edición local contrasta enormemente con la realidad. Tras esta digresión, volvamos a nuestra muestra objeto de estudio.

Puesto que lo que nos interesa es analizar si efectivamente las traducciones al español de autores quebequenses circulan en el continente americano tras ser publicadas en España (ya sea por medio de la distribución o de la coedición), hemos seleccionado una muestra del corpus mencionado que incluye traducciones que satisfacen dos criterios: 1) traducciones cuyos originales han sido un éxito de ventas en Quebec ${ }^{9}$ y 2) traducciones que han sido publicadas por editoriales que pertenecen a conglomerados editoriales españoles que tienen sellos o sucursales en el continente americano.

¿Por qué limitarnos, de momento, a bestsellers y a conglomerados editoriales? A los primeros porque, en principio, aunque el éxito no se transfiere de un país a otro, los bestsellers tienen más potencial de difusión internacional que otro tipo de títulos. Y a conglomerados editoriales porque, en principio también, estos actores tienen más probabilidades y medios de distribuir o coeditar en América Latina o en Estados Unidos una traducción publicada en España que las editoriales pequeñas o medianas, que suelen tener una distribución limitada. Al fin y al cabo, es bien sabido que el principal problema de las editoriales de talla mediana y pequeña es la distribución. Asimismo, son precisamente estos conglomerados editoriales los que se pueden permitir comprar derechos mundiales de traducción al español, lo cual significa que no hay restricciones legales para que las traducciones circulen en todos los países del ámbito hispánico. En este sentido, en la muestra que nos ocupa, encontramos representados

\footnotetext{
${ }^{9}$ Todas ellas han vendido al menos diez mil ejemplares, lo que en Quebec se considera un bestseller.
} 
a los tres gigantes del mercado editorial contemporáneo en lengua española: Grupo Planeta, Random House Mondadori y Santillana, así como un caso del Grupo Anaya.

\section{Grupo Planeta}

Es el grupo editorial más representado en la muestra seleccionada para este artículo. La editorial Planeta, origen del Grupo Planeta, fue fundada en 1949 en Barcelona por José Manuel Lara. Entre los años cincuenta y sesenta empieza la expansión extranjera, y hoy en día cuenta con filiales comerciales y productivas (es decir, sellos locales) en Argentina, México, Chile, Colombia, Brasil, Uruguay y Perú. Hay que destacar asimismo su expansión multimedia: este grupo tiene en su poder la mayoría de las acciones del periódico español La razón, la cadena de televisión española Antena 3, la cadena de librerías Casa del Libro, la emisora de radio Onda Cero, el periódico colombiano El tiempo, la cadena de televisión bogotana CityTV, la academia de idiomas Home English, la revista Playboy, por no citar sino los casos más conocidos.

Empecemos el recorrido de nuestra muestra seleccionada por la novela Puta, de la autora quebequense Nelly Arcan, que vendió más de ochenta mil ejemplares en francés (Laurin, 2004: IV) y se tradujo a más de una docena de lenguas. En español, fue publicada en 2003 por el prestigioso sello Seix Barral, propiedad del Grupo Planeta, y en 2005 la reeditó en edición de bolsillo precisamente el sello De Bolsillo del Grupo Planeta, Booket. En España se vendieron dos mil novecientos ejemplares de la traducción española (Booket, 2007), y la recepción crítica, a diferencia del original, fue muy limitada. ${ }^{10}$ En cuanto a su segunda vida en América Latina, según los datos obtenidos a partir de los catálogos web de Planeta en los países latinoamericanos donde tiene filiales, la traducción no se ha coeditado o reimprimido en suelo latinoamericano. Estos datos se han triangulado con las páginas web de ciertas librerías seleccionadas, ${ }^{11}$ así como las páginas de las bibliotecas nacionales de esos mismos

${ }^{10}$ Véase Córdoba Serrano (2013: 133-140) para un análisis más detallado de esta traducción y de su recepción en España.

${ }^{11}$ Desde el punto de vista metodológico, a la hora de estudiar la circulación internacional de las traducciones peninsulares seleccionadas en América Latina, las librerías se presentan como un elemento clave para la recopilación de datos (agradecemos a Graciela Martínez-Zalce esta valiosa pista), ya que en la mayoría de los países de la región no se respeta la Ley del Depósito Legal, según la cual la editorial está obligada a depositar en la biblioteca nacional de su país correspondiente ( $y$, por lo tanto, a dejar constancia de) todos los ejemplares que imprime o coedita. Asimismo, según dicha ley, se depositan en las bibliotecas nacionales los ejemplares impresos o coeditados en un país concreto, pero no los libros que simplemente se distribuyen en dicho país. Todo ello explica la importancia de tener en cuenta las librerías a la hora de recopilar datos sobre la circulación y la presencia de las traducciones objeto de estudio en suelo americano. Con respecto a las librerías consultadas, nos hemos servido de una muestra no probabilística opinática de sujetos (se seleccionaron expertos o individuos muy familiarizados con el mundo del libro y la traducción 
países latinoamericanos donde Planeta está presente, ${ }^{12}$ y hemos podido comprobar que Planeta no distribuyó ni coeditó Puta por medio de sus sellos locales. Dicha traducción sólo se distribuyó en Argentina y en Chile en su momento (en la actualidad, este título está agotado), pero se trató simplemente de exportaciones muy puntuales a petición expresa de dos librerías muy concretas, Santa Fe (en el caso de Argentina) y Feria Chilena del Libro (en el caso de Chile). ${ }^{13}$ La propia Seix Barral nos indicó (Seix Barral, 2013) que la traducción no se había distribuido en América Latina, es decir, que Planeta Argentina (que suele ser el centro difusor de los títulos de Planeta en el Cono Sur) no había seleccionado específicamente este título para distribuirlo o coeditarlo, lo que confirma que se trató de un pedido muy puntual de las dos librerías mencionadas. Santa Fe es, de hecho, una librería que, como ellos mismos destacan en su página web, "se caracterizó -y se caracteriza- por ofrecer un especial surtido de libros importados, gracias a las buenas relaciones que mantienen con proveedores del exterior" (Librería Santa Fe, s. f.). Es posible que la decisión de esta librería se basara en el interés en Argentina por el psicoanálisis y el hecho de que esta novela sea el testimonio en forma de diario íntimo que la protagonista, una prostituta de lujo, le escribe a su psicoanalista.

El siguiente caso de nuestra muestra es Un domingo en la piscina en Kigali, de Gil Coutermanche, que ha vendido hasta la fecha dos millones de ejemplares (éxito que pasa por Random House y su traducción al inglés), y se ha traducido a veintitrés lenguas. La traducción española fue publicada en el 2003 por el sello Emecé, también propiedad del Grupo Planeta, y vendió menos de dos mil ejemplares, en concreto, 1942 (Furió, 2013). Al consultar en los catálogos en línea de Planeta en los países latinoamericanos ya mencionados, en las páginas de las librerías también mencionadas, así como en los de las bibliotecas nacionales en cuestión, no vemos tampoco rastro alguno de la presencia de este libro fuera de la Península Ibérica. Esto no significa que un lector latinoamericano no pueda haber adquirido la traducción por medio de una compra por Internet o por pedido específico a una librería de gran difusión, o en ferias internacionales del libro (por ejemplo, la Feria Internacional de Guadalajara es un momento propicio para adquirir ciertos libros traducidos importados sin pagar gastos de envío).

editorial: profesores de literatura y de humanidades en general, así como traductores) para identificar qué librerías seleccionar, y nos hemos limitado a las dos por país que, en opinión de los expertos consultados, son las más propensas a vender traducciones importadas o traducciones en general de narrativa internacional. En concreto, las librerías seleccionadas han sido las siguientes: Gandhi y Fondo de Cultura Económica (México), Librería Santa Fe y el Ateneo Grand Splendid (Argentina), Lerner y Librería Nacional (Colombia), Crisol e Ibero (Perú), Feria Chilena del Libro y Librería Universitaria (Chile), y Papacito y Yenny (Uruguay).

${ }^{12}$ En el caso de Planeta, en Argentina, Chile, Colombia, México, Perú y Uruguay.

${ }^{13}$ En el caso de Chile, su precio es incluso más elevado que su equivalente en euros, lo cual lo convierte en un objeto de lujo al alcance de muy pocos. 
El último caso de la muestra seleccionada, publicado por un sello del Grupo Planeta, es Cómo hacer el amor con un negro sin cansarse, de Dany Laferrière, que no sólo vendió diez mil ejemplares en Quebec (Warmuzińska-Rogóż, 2009: 204), sino que su versión cinematográfica en inglés creó asimismo todo un tumulto mediático en Estados Unidos. La traducción española fue publicada en 1997 por Destino, también propiedad del Grupo Planeta, y en España vendió sólo setecientos setenta y ocho ejemplares (Ruiz, 2011). Al consultar en todas las fuentes ya mencionadas, sólo hemos encontrado rastros de este libro en la Librería Santa Fe, en Argentina, la misma donde hallábamos Puta. De nuevo, más que de esfuerzos concretos por parte de Planeta o de sus filiales para proyectar este título en América Latina, se trata de un caso aislado, de una librería puntual que suele hacer pedidos de libros muy selectos a los distribuidores, lo que no significa que el libro tuviera una gran difusión en Argentina, en el Cono Sur, o en América Latina en general.

Había que esperar hasta $2012^{14}$ para que un sello perteneciente a otro conglomerado editorial, esta vez Alianza Editorial, del Grupo Anaya, publicara de nuevo otra novela de Dany Laferrière en España: nos referimos a El enigma del regreso. Se trata de un título que, como bien indica la cubierta de la traducción española, le valió a su autor el prestigioso galardón francés Médicis en 2009, así como una recepción crítica nada desdeñable en España, incluido un número importante de reseñas en redes sociales españolas, pero también en suplementos culturales y revistas literarias de prestigio. Desde el punto de vista comercial, sin embargo, la traducción sólo ha vendido setecientos ejemplares en España (Juanas, 2013). En América Latina, de las fuentes consultadas, sólo está disponible en el catálogo de las librerías mexicanas Gandhi y Fondo de Cultura Económica, ${ }^{15}$ y su precio en pesos mexicanos es equivalente al precio en euros, con lo que, como en otros casos anteriores, se puede considerar un objeto de lujo al alcance de pocos. En cuanto a Argentina, a pesar de que Alianza tiene una filial en este país y a pesar de que la editorial argentina Aique, también perteneciente al Grupo Anaya, alberga entre sus fondos un número considerable de títulos de Alianza Editorial, no encontramos rastro alguno de este libro en su catálogo. La recepción crítica recibida en España no parece justificar mayores esfuerzos para que el título se distribuya (y aún menos se coedite) en el continente americano. Esta distribución limitada explica seguramente que fuera de España el libro sólo haya vendido trescientos ejemplares, según nos informa Pilar Juanas (2013), del Departamento de Publicaciones de Alianza Editorial.

\footnotetext{
${ }^{14}$ En 2004 se publicó Esta granada en manos del joven negro ¿es un arma o una fruta?, pero esta vez en la editorial independiente Ediciones El Cobre.

${ }^{15}$ La presencia del Grupo Anaya en América Latina a través de filiales como Alianza y Aique en Argentina se ha visto reforzada en 2007 con la adquisición del 100 por ciento del Grupo Editorial Patria de México.
} 


\section{Grupo Santillana}

El siguiente caso que responde a los criterios de selección identificados anteriormente es la novela $R u$, de Kim Thúy, que vendió ciento veinte mil ejemplares en Quebec. En España fue publicada en 2010 por el prestigioso sello literario Alfaguara, del Grupo español Santillana.

La temprana vocación americanista es algo que ha caracterizado a este grupo desde sus orígenes y es una pieza central en su imagen de marca. Rodríguez Marcos (2011) describe así los orígenes del Grupo Santillana:

[...] en 1963 [Jesús de Polanco] había volado a Santiago 'con una maleta llena de libros'. Por entonces acababa de abrir en Argentina una pequeña filial de la editorial que, tres años antes, había fundado en España. En recuerdo de sus orígenes cántabros y de los de su socio, la había llamado Santillana. [...] En América abría la oficina de Nueva York (1968) y continuaba una implantación internacional que hoy se extiende a 22 países.

El sello en el que se publicó $R$ u, Alfaguara, pertenece justamente al Grupo Santillana y, a su imagen y semejanza, llegó a convertirse "no en un sello español con delegaciones en América, sino en un sello tan americano como español [...En Alfaguara] consolidamos [...] una imagen doble: global y local a la vez. Los argentinos saben que en Alfaguara tienen una editorial argentina. El mejor ejemplo de esa política es que la directora actual del sello en España es alguien que dirigió el sello en Colombia. [...] Esa directora es Pilar Reyes, que recuerda que, salvo García Márquez, todos los escritores del boom han publicado en Alfaguara: de Vargas Llosa a Carlos Fuentes pasando por Cortázar, Mutis o José Donoso" (Rodríguez Marcos, 2011).

Alfaguara está presente, ya sea por medio de filiales comerciales o productivas, en Bolivia, Chile, Colombia, Costa Rica, Nicaragua, Panamá, Ecuador, Guatemala, El Salvador, Honduras, México, Paraguay, Perú, República Dominicana, Uruguay, Estados Unidos y Venezuela.

En cuanto a $R u$, a pesar de esta implantación arraigada de Alfaguara en el continente americano, del hecho de que esta editorial tenga los derechos mundiales en lengua española de la novela y de que su traducción recibiera una atención considerable por parte de los medios de comunicación españoles, no encontramos fuera de España rastro de ésta en ninguno de los catálogos web de Alfaguara en los países de lengua hispana donde esta editorial tiene presencia ni tampoco en las bibliotecas nacionales de estos países o en librerías. Parece que los tres mil trescientos ejemplares que esta traducción vendió en España (Fasce Ferri, 2013) son el motivo por el cual no les interesara invertir más en proyectar este título fuera de ese país: sencillamente no eran suficientes. 


\section{Random House MondadorI}

El único título de nuestra muestra de traducciones que ha tenido una amplia proyección y circulación en América Latina es El frío modifica la trayectoria de los peces, primera novela del autor francés afincado en Quebec Pierre Szalowski. Dicha traducción -que vendió veinticinco mil ejemplares en España (ANEL, 2011)_ ${ }^{16}$ fue publicada por el sello Grijalbo en 2009 y reeditada en 2010 en edición de bolsillo por Debolsillo. Actualmente, ambos sellos forman parte del grupo Random House Mondadori (que a su vez pertenece al gigante Random House). ${ }^{17}$ Curiosamente, es un caso en el que el éxito de ventas de la traducción española de este grupo legitima el original: la traducción vende quince mil ejemplares más que el original, lo cual es algo excepcional para un título quebequense y, curiosamente, a diferencia de lo que mencionábamos al principio de este artículo, es el "paso" por España lo que ayuda a que el libro se publique en Francia.

En el mundo hispanohablante y en lo que a narrativa se refiere, Random House Mondadori es el mayor competidor de Planeta. Dicho grupo cuenta con una presencia notoria en América Latina, como ellos mismos describen en su página web: "Random House Mondadori está estructurado en tres divisiones geográficas: España; Cono Sur, con empresas en Argentina, Chile y Uruguay; y Zona Norte, con presencia en México y Colombia" (Random House Mondadori, s. f.).

El éxito de ventas en España de esta ópera prima de Szalowski parece claramente justificar que dicha traducción esté disponible en América Latina en el catálogo de Random House México, Argentina, Chile, Uruguay, Venezuela y Colombia, que se pueda comprar en divisa local y a precios comparables con la producción local, lo que no quiere decir que esté al alcance de la mayoría, ya que, como bien dice Manuel Gil, "[...] el libro en papel en América es un asunto de rentas muy altas" (2013). También hemos encontrado este título disponible, por ejemplo, en los catálogos de las librerías peruanas en línea que habíamos seleccionado anteriormente, a pesar de que Random House Mondadori no tenga filiales comerciales o productivas en este país. Encontramos asimismo numerosas reseñas y videos sobre este título en redes sociales y blogs a lo largo y ancho de América Latina, especialmente en México, donde, por ejemplo, fue una lectura recomendada en algunas escuelas y apareció reseñado en revistas digitales y en múltiples blogs sobre pedagogía y literatura infantil y juve-

\footnotetext{
${ }^{16}$ Esto se considera un éxito rotundo de ventas para una traducción, sobre todo teniendo en cuenta que en 2010 la tirada media por libro en España se colocó en solamente 1734 ejemplares y 2750 en 2009 (Observatorio de la Lectura y el Libro, 2012: 12), sin contar con que normalmente no se venden todos los ejemplares de una tirada.

${ }^{17}$ Véase la lista detallada de los integrantes de Random House (s. f.).
} 
nil. Asimismo, se trata de un título que se ha utilizado en las clases de español como lengua extranjera, por sólo citar algunos ejemplos de la vasta circulación internacional de este libro que hemos observado en nuestras búsquedas.

La presencia de esta obra en América Latina se da generalmente vía coedición por parte de las divisiones latinoamericanas de Random House (es decir, no se acude a la distribución). Pero en el marco del espectro de coedición presentado anteriormente, nos situamos en el primer peldaño: en México, por ejemplo, la traducción se imprime en este país, la promueve y vende Random House México, quien le cambia asimismo la cubierta, pero no se lleva a cabo ningún tipo de adaptación lingüística o cultural de la traducción española para adecuarla a los lectores mexicanos. Así lo resume uno de ellos en el blog Bookcrossing (2010): “ [...] a pesar de que la edición está impresa en México, la traducción es española, por tanto, tiene modismos y palabras que en México no se utilizan mucho; sin embargo, se pueden leer y entender las palabras por el contexto o si se tiene más dudas, se puede recurrir a 'San Google' y listo". En resumidas cuentas, aun cuando un título se coedita en América Latina, el tipo de coedición que se lleva a cabo se asemeja a la distribución tradicional.

A pesar de su diversidad (temas, autores y sellos distintos), nuestra muestra pone de manifiesto un patrón recurrente: en todos y cada uno los casos observados, el único criterio decisivo a la hora de determinar los esfuerzos editoriales en materia de proyección de una traducción en América Latina parece ser de índole económica: el éxito de público en suelo ibérico. Y por éxito de público se suele entender ventas de al menos veinte mil ejemplares (Guitart, 2013). Todo ello a pesar del discurso general de los editores, ${ }^{18}$ quienes sostienen que las ventas de una traducción dada en España pueden ser un criterio que influya sobre la proyección de dicho título en el continente americano, pero no uno concluyente: "Todo depende del libro", reiteran; sin embargo, recordemos que El enigma del regreso, de Dany Laferrière, que tuvo una recepción crítica muy aceptable en España, no se coeditó (ni apenas se distribuyó) en América Latina. Asimismo Ru, de Kim Thúy, recibió una atención mediática y crítica importante en España, ha vendido hasta la fecha más de tres mil ejemplares (lo cual no está nada mal, teniendo en cuenta que la tirada media por libro del año en el que se publicó no superaba los dos mil ejemplares) ni tampoco ha logrado cruzar el Atlántico. Solamente la novela de Pierre Szalowski, que efectivamente vendió más de veinticinco mil ejemplares en España, lo ha logrado, y aun así se trata de una versión

\footnotetext{
${ }^{18}$ En el marco de nuestro proyecto de investigación "Coedición de traducciones en el espacio hispánico", hemos entrevistado hasta la fecha a varios sellos del Grupo Planeta (en concreto a GeoPlaneta, Seix Barral, Minotauro, Destino y Emecé), y una de las preguntas de las entrevistas versaba precisamente sobre los criterios que consideraban importantes a la hora de proyectar, y más concretamente coeditar, una traducción peninsular en América Latina y Estados Unidos.
} 
sin ningún tipo de localización lingüística y cultural, sino algo que se asimila enormemente a la distribución tradicional de traducciones importadas. Parece que el umbral que mencionaba Guitart (2013), directora editorial de Emecé, sobre lo que constituye un éxito, es decir, ventas de al menos veinte mil ejemplares, no es nada exagerado.

Que el número de ejemplares vendidos sea un criterio determinante para los grandes grupos editoriales a la hora de decidir el grado de difusión transatlántica que se da a un título (y si coeditarlo o no), no es de extrañar ni somos los primeros en sacar a la luz este hecho. Que sea el único criterio, al menos a partir de los datos empíricos con los que contamos de momento, es quizá más preocupante y, hasta ahora, a mi entender, no se ha reflexionado lo suficiente sobre las consecuencias concretas que este tipo de prácticas conllevan sobre todo para las literaturas periféricas, y en nuestro caso en particular, para la difusión internacional de la narrativa quebequense. Cabe asimismo destacar que muchos de los títulos de esta muestra son traducciones pertenecientes al campo de producción restringida ${ }^{19} \mathrm{y}$, por lo tanto, títulos de los que, ya de entrada, no se deberían esperar grandes ventas, con lo cual es paradójico que esto sea un criterio concluyente a la hora de planear su difusión en el ámbito hispánico.

¿Quiere todo esto decir que, aun sabiendo que un título tiene pocas probabilidades de ser difundido en América Latina y en Estados Unidos, los grupos editoriales españoles compran derechos mundiales de todas formas, por si tocara la flauta? A partir de la muestra analizada, nuestra respuesta es afirmativa. Comprar los derechos de traducción para todo el ámbito hispánico conlleva, además, otra consecuencia: si un editor latinoamericano independiente quiere distribuir, coeditar o incluso retraducir un texto para darle una segunda oportunidad en suelo americano, le es imposible desde el punto legal. Y, en el mejor de los casos (es decir, si al grupo editorial que publicó la traducción en España ya no le interesa el título y está dispuesto a ceder los derechos para su difusión en el continente americano), el editor independiente tendría que comprar los derechos a gigantes como Planeta, Random House Mondadori o Santillana a precios probablemente nada módicos, lo cual es poco probable. En conclusión, más que una puerta de entrada al mercado americano, la compra de

\footnotetext{
${ }^{19}$ Según Bourdieu, en el campo de la producción cultural, se pueden distinguir dos subcampos, que se oponen y complementan al mismo tiempo: el campo de producción restringida y el de gran producción. El campo de producción restringida se rige por una lógica no comercial y en él se produce para otros productores, es decir, para otros autores, críticos literarios, profesores de literatura, etc. El de gran producción tiene como destinatario al gran público y se rige por una lógica comercial, es decir, una que se somete a las leyes del mercado. Hoy en día, dada la feroz competencia que reina, muchos sellos, incluso los más literarios, suelen combinar ambas lógicas: publican bestsellers, que van a producir beneficios importantes, para después poder apostar por títulos no comerciales. Son estos últimos títulos los que dotan de capital simbólico (y no necesariamente económico) a una editorial, pero, como indica Bourdieu, a largo plazo, el capital simbólico suele convertirse en capital económico (Bourdieu, 1998).
} 
derechos mundiales en español de autores quebequenses por parte de los grandes grupos editoriales españoles imposibilita, o como mínimo obstaculiza, la segunda vida de una traducción en América Latina.

\section{OtROS DERROTEROS ALTERNATIVOS}

¿Pero existen otras alternativas? Aunque sólo sea a modo de comparación y someramente, en este último apartado es importante volver a nuestro corpus y examinar los bestsellers de narrativa quebequense publicados en España por otro tipo de actores del mundo editorial: los editores independientes. Encontramos en concreto dos ejemplos: La niña que amaba las cerillas, de Gaétan Soucy, traducción publicada por Ediciones Akal en 2001, una editorial española independiente de tamaño mediano, y en segundo lugar, Nikolski, de Nicolas Dickner, publicada por la pequeña editorial vasca Txalaparta en 2012.

En el primer caso, a pesar de haber vendido sólo mil trescientos ejemplares en España, ${ }^{20}$ la traducción se puede adquirir por medio del catálogo de Akal México a 103 pesos, al igual que las otras traducciones del mismo autor publicadas por Akal ( $\mathrm{La}$ absolución, La Inmaculada Concepción y ¡Music-hall!). Si bien es cierto que la traducción que se vende en México es la misma que la publicada en España, conviene aclarar que es del chileno Óscar Luis Molina: salvo el uso del pronombre personal de segunda persona del plural vosotros, la traducción está poco marcada desde el punto de vista diatópico. No hay prácticamente españolismos que puedan crear una cierta distancia o extrañamiento para el lector mexicano. Como nos indicó el propio Espino (2013), los títulos que se publican en México son los mismos que los de España, pero a partir del otoño del 2014, tenían "pensado desarrollar desde México una línea de publicaciones específica para América Latina”. Añadió asimismo que desde el 2011 también tienen una oficina comercial en Argentina, el germen de un futuro Akal Argentina, que se convertirá en una filial productiva en los próximos años.

En cuanto a Nikolski, se trata de un caso en el que desde el primer momento la editorial vasca Txalaparta tenía en mente no sólo la difusión y circulación de la traducción en otros países hispanohablantes fuera de España, sino incluso la publicación simultánea de esta traducción en varios de estos países gracias a la red de Editores Independientes de la que forma parte (Ruiz, Mari Jose, 2010), red que está constituida por la editorial vasca Txalaparta, la mexicana ERA, la chilena Lom y la uruguaya Trilce.

\footnotetext{
${ }^{20}$ Véase Espino (2008). Para un análisis más detallado de esta traducción, tanto sobre el cómo y el por qué fue seleccionada por Akal, así como algunos aspectos relacionados específicamente con la recepción y la traducción en sí, véase Córdoba Serrano (2013: 253-268 y 140-142).
} 
De hecho, la idea inicial de Txalaparta era la compra conjunta por parte de las cuatro editoriales de los derechos de traducción de Nikolski para todo el ámbito hispánico y coeditar simultáneamente la traducción en sus países respectivos, es decir, coproducir la traducción, pero, puesto que a sus homólogos "no les causó el entusiasmo que despertó en Txalaparta", ésta "se lanzó sola a la piscina" y prosiguió con su idea de comprar los derechos para todo el ámbito hispánico, ya que era "posible que, una vez que ya est[uviera] traducida y editada, pu[diera] interesarles" (Ruiz, Mari Jose, 2011). Se trataría pues de un caso de coedición en diferido (Legendre, 2007; Buzelin, 2006), como lo han hecho con otras traducciones. ${ }^{21}$ Por ejemplo, es el caso de la novela $L a$ prohibida, de la argelina Malika Mokkedem, publicada por Txalaparta en 2003 y coeditada por ERA tres años más tarde. Lo interesante de este último caso es que no se trata de un mero acuerdo de difusión entre Txalaparta y ERA, sino que cuando ERA coedita La prohibida en México en 2006, no sólo cambia la cubierta de la traducción, la imprime en suelo mexicano y la hace circular con su logo e imagen de marca (al fin y al cabo el público de este país deposita mucha más confianza en ERA, cuya trayectoria es muy conocida en este país), sino que, además, aun partiendo de la traducción peninsular, ERA la "limpia" de españolismos ${ }^{22}$ y la adapta a su nuevo público local mexicano. ${ }^{23}$ Se trata, pues, de un proyecto que implica una adaptación lingüística y cultural mucho más esmerada de lo que veíamos en algunos casos anteriores de traducciones publicadas por conglomerados editoriales.

Volviendo al caso de Nikolski, después de una negociación compleja con el agente literario de Dickner, Txalaparta únicamente logró adquirir los derechos de traducción para España, lo que significa que los derechos para el resto de los países hispanohablantes siguen disponibles y, por lo tanto, sigue la puerta abierta para que la traducción pueda disfrutar de una segunda vida en el continente americano. Como hace con todas sus obras, el ideal de Txalaparta es que sus homólogos latinoamericanos se interesen por sus traducciones tarde o temprano. En el caso de Nikolski en concreto, al no tener los derechos mundiales en español, Txalaparta espera que la editorial latinoamericana homóloga negocie los derechos de autor en español para su territorio con el editor quebequense y, una vez hecho eso, ella estaría dispuesta a facilitarles la traducción a cambio de poder hacer lo mismo en el otro sentido, es decir, a cambio de que sus so-

${ }^{21}$ Véase en la página de Editores Independientes (s. f.) una lista exhaustiva de los proyectos de coedición llevados a cabo por estos cuatro editores.

${ }^{22}$ Es cierto que ya de por sí, sobre todo en prosa, el español de esta traducción no está muy marcado desde el punto dialectal.

${ }^{23}$ Podemos encontrar cambios léxicos, pero también morfosintácticos (sobre todo tiempos verbales: por ejemplo, el uso del pretérito perfecto simple es remplazado por el indefinido), y también ortotipográficos (el uso de comillas latinas pasa al uso más extendido de comillas inglesas en México), por no mencionar sino los cambios más notorios. 
cios le cedan los derechos de algunos de sus títulos para que Txalaparta pueda publicarlos en España (Ruiz, Mari Jose, 2011). Estas redes de editores independientes se basan por lo tanto en la reciprocidad y la buena voluntad de sus miembros para promover lo más posible tanto sus títulos originales como sus traducciones fuera de su territorio, lo cual contrasta con lo observado anteriormente en el caso de los conglomerados editoriales. Si los socios de Txalaparta no acabaran interesándose por su traducción -es pronto para saberlo, a juzgar por la demora que se observa en otros proyectos de coedición llevados a cabo por la Red de Editores Independientes-, siempre existe la posibilidad de que otros editores latinoamericanos o hispanounidenses que no tienen nada que ver con Txalaparta se interesen por la obra traducida, compren al editor quebequense los derechos para su territorio y después decidan si quieren retraducir completamente la novela para su público o comprar la traducción a esta editorial y revisarla para adaptarla a su público local concreto. Lo interesante es que son muchas las puertas que han quedado abiertas.

Estos resultados son preliminares, y ciertamente es necesario un análisis más a profundidad de las prácticas de los editores independientes en materia de distribución y coedición internacional de sus traducciones, para ver si el caso de Txalaparta es algo aislado o si se trata de una tendencia del sector editorial independiente, pero, de momento, nuestro análisis parece indicar que cuando la narrativa quebequense cae en manos de los grandes grupos editoriales españoles, España no es una puerta de entrada a América Latina, sino más bien una barrera. También hemos observado que incluso cuando estos grandes grupos distribuyen o coeditan traducciones de narrativa quebequense en América Latina, se trata de una edición peninsular que el lector latinoamericano, a pesar de entender, suele sentir como extraña. Las ventas limitadas de las traducciones analizadas no parecen justificar la inversión por parte de estos grupos en una nueva revisión y adaptación lingüística y cultural para los países de habla hispana. Muy distinto era el caso de Minotauro mencionado anteriormente, en el que las ventas potenciales en ciertos países latinoamericanos sí parecían justificar este trabajo de adaptación. En este sentido, cabe compartir la crítica que profiere Silvia Senz (citada en Gil, 2013), conocida por su famoso blog Addenda \& Corrigenda, sobre "el cinismo con que el sector editorial español ha representado la pamema de la unidad panhispánica [...] por tierras americanas y el descuido absoluto de la localización lingüística de las obras traducidas al español publicadas en España y vendidas en América Latina", un aspecto que ciertamente merece mayor atención en artículos futuros.

A modo de conclusión, esperamos que, al poner en tela de juicio el mito según el cual España es para los autores quebequenses una puerta de entrada al mercado lati- 
noamericano e hispanounidense, podamos orientar la elaboración de futuras políticas del gobierno federal canadiense y del gobierno provincial quebequense en materia de internacionalización del libro canadiense en general, y en particular, sobre todo de cara a una mejor planificación de su incursión en el mercado americano de habla hispana. Este estudio evidencia que lo más importante, más allá de criterios geográficos, es poner el punto de mira en la edición independiente -ya sea directamente en las editoriales latinoamericanas o, en su defecto, en las editoriales españolas que tienen sólidas redes sociales en América Latina, o en ambas- ${ }^{24}$ y fomentar la compra de derechos por parte de estos actores del mundo editorial. Todo ello se podría hacer realidad no sólo por medio de subvenciones a la traducción, procurando dar prioridad a los editores independientes a la hora de otorgarlas, ${ }^{25}$ sino haciendo algo más importante aún: creando subvenciones que ayuden a los pequeños editores independientes a competir con los conglomerados editoriales por la compra de derechos de traducción. Huelga, asimismo, incidir en la importancia de educar a autores, editores $u$ otros actores quebequenses del mundo de la edición y hacerles ver que vender sus derechos a Planeta, por ejemplo, no garantiza su presencia y proyección fuera de España (que es al fin y al cabo, un mercado pequeño y saturado). Esperemos que estudios como éste y otros similares ${ }^{26}$ abran más los ojos en este sentido.

${ }^{24}$ En realidad, no tenemos datos como para afirmar que un editor independiente, digamos mexicano, pueda llevar a cabo una mejor labor de distribución en otros países latinoamericanos que un editor independiente español con una sólida red de contactos para coeditar o distribuir en América Latina. De hecho, sabemos que uno de los principales problemas en América Latina es la distribución y que, en ocasiones, adquirir en una librería chilena un título publicado en España es más fácil que comprar un título de la vecina Argentina.

${ }^{25}$ A pesar de esta dinámica, es interesante constatar cómo los grandes grupos editoriales españoles están bien representados en la lista de editoriales que han recibido subvenciones del Consejo de las Artes de Canadá para traducir autores canadienses. Por ejemplo, del 2004 al 2012, encontramos representadas editoriales de la talla de RBA, Planeta, Alianza, Random House Mondadori, etc. Es cierto que el número de editoriales independientes representadas es también importante (como, por ejemplo, Ediciones de Intervención Cultural, Takusan, Libros del Asteroide, etc.), pero muchas de ellas son editoriales españolas con una presencia muy limitada en América Latina. A su vez, tan sólo encontramos en el periodo observado una traducción mexicana subvencionada y tres en Argentina, en comparación con las sesenta traducciones peninsulares subvencionadas durante el mismo periodo. Es cierto que son las editoriales las que tienen que solicitar estas subvenciones a la traducción y no el Consejo quien selecciona a las editoriales, pero también es cierto que tener a España como punto de mira por parte de los editores y gremios editoriales canadienses y quebequenses podría explicar que este programa de subvenciones se conozca mucho mejor en la Península Ibérica que en América Latina. Agradecemos a Catherine Montgomery, gestora del programa de subvenciones a la traducción internacional del Consejo de las Artes de Canadá, haber puesto a nuestra disposición estos datos sobre subvenciones a la traducción al español concedidas por el Consejo entre 2004 y 2012.

${ }^{26}$ En este sentido, son interesantes las investigaciones que se están llevando a cabo en el marco del proyecto "Canada in Latin America", dirigido por los profesores Luise von Flotow, Marc Charron y Hugh Hazelton. Para más información, véase la página oficial del proyecto (Canada in Latin America, s. f.). 


\section{FUENTES}

Association Nationale des Éditeurs de Livres (Anel)

2011 "Québec édition: le développement international", en <http:/ / www.anel. qc.ca/ledition-au-quebec/ histoire-du-livre-et-de-ledition-au-quebec/ > , consultada el 10 de agosto de 2014.

\section{BOOKCROSSING}

2010 enero, en <http: / / www.bookcrossing.com/journal/7746800>, consultada el 10 de agosto de 2014.

BOOKET

2007 "Puta", comunicación vía correo electrónico, 15 de mayo.

Bourdieu, PiERre

1998 Les Règles de l'art. Genèse et structure du champ littéraire, edición revisada y corregida, París, Seuil.

\section{BuZELIN, HélÈNE}

2006 "Independent Publisher in the Networks of Translation", TTR, vol. 19, no. 1, pp. 135-174.

\section{Canada in Latin America}

s.f. <http://artsites.uottawa.ca/canada-latin-america/en/>, consultada el 10 de agosto de 2014.

\section{Casanova, Pascale}

1999 La République mondiale des Lettres, París, Seuil.

Centro Regional para el Fomento del Libro en América Latina y el Caribe (Cerlalc)

2012 El espacio iberoamericano del libro 2012, Bogotá, en <http: / / www.cerlalc.org/ files/tabinterno/1d493d_Espacio_2012_digi_def.pdf $>$, consultada el 10 de agosto de 2014.

2006 El espacio iberoamericano del libro 2006, Bogotá, en <http: / / www.cerlalc.org / secciones / libro_desarrollo/Panorama.pdf $>$, consultada el 10 de agosto de 2014.

Córdoba Serrano, María Sierra

2013 Le Québec traduit en Espagne: analyse sociologique de l'exportation d'une culture 
périphérique (Translation Series, Regards sur la traduction), Ottawa, University of Ottawa Press.

2010 "Translation as a Measure of Literary Domination: The Case of Quebec Literature Translated in Spain (1975-2004)", MonTi Monografías, vol. 2, pp. 249-282.

EDITORES INDEPENDIENTES

s.f. <http: / / www.editoresindependientes.com/ publicaciones/>, consultada el 10 de agosto de 2014.

ESPINO, JESÚs

2013 "Pregunta sobre la presencia de Akal en América Latina y en EE.UU.", comunicación vía correo electrónico, 25 de julio.

2008 Entrevista con la autora, Madrid, 14 de enero.

FASCE FERRI, MARÍA

2013 "Preguntas", comunicación vía correo electrónico, 22 de julio.

FERNÁNDEZ MOYA, MARÍA

2012 "Creating Knowledge Networks: Spanish Multinational Publishers in Mexico", Business History Review, vol. 86, no. 1, pp. 69-98.

2009 "Editoriales españolas en América Latina. Un proceso de internacionalización secular", Información Comercial Española (ICE), vol. 849, pp. 65-78.

2008 "Editores españoles a ambos lados del Atlántico", Historia del presente, segunda época, vol. 12, pp. 97-110.

Furió, MARÍA JosÉ

2013 “Información Kigali”, comunicación vía correo electrónico, 22 de julio.

GIL, MANUEL

2013 "El claroscuro americano", Antinomiaslibro (marzo), en <http:/ / antinomiaslibro.wordpress.com/2013/03/19/ claroscuro-americano/>, consultado el 10 de agosto de 2014.

GuITART, MaríA

2013 Entrevista con la autora, 24 de julio. 
ICEX ESPAÑA EXPORTACIÓN E INVERSIONES

2012 El sector editorial en México, México, Oficina Económica y Comercial de la Embajada de España en México.

JuAnas, PiLAR

2013 "Información sobre El enigma del regreso", comunicación vía correo electrónico, 16 de julio.

King Daum, Juliet

2005 Selling Canadian Books in Spain, Ottawa, Association for the Export of Canadian Books.

LAURIN, DANIELLE

2004 "Une longue lettre à l'homme aimé", Le Monde, 15 de octubre, p. IV.

LEGENDRE, BERTRAND

2007 Les métiers de l'édition, París, Electre-Ed. du Cercle de la Librairie.

Librería SANTA FE

s.f. <http: / / www.lsf.com.ar/about_us.aspx>, consultada el 10 de agosto del 2014.

LIONETTI, JULIETA

2012 “E-Books in Spanish Latin America: The New El Dorado or a Mirage?", Publishing Perspectives, 29 de agosto, en <http://publishingperspectives.com 2012/08/ e-books-in-spanish-latin-america-the-new-el-dorado-or-a-mirage / >, consultada el 10 de agosto de 2014.

LÓPEZ JARA, JOSÉ

2013 Entrevista con María Rierra (asistenta de investigación de la autora), Barcelona, 11 de junio.

\section{OBSERVATORIO dE LA LeCTURA y EL LiBRo}

2012 El sector del libro en España 2010-2012, Madrid, Ministerio de Educación, Cultura y Deporte, en <http: / / www.mcu.es / principal / docs / MC / 2012/Libro/ Sector_del_Libro_Abril_2012.pdf $>$, consultada el 10 de agosto de 2014.

2007 "Pour une 'littérature-monde' en français", Le Devoir, 24 de marzo, p. f2. 
RAMÍREZ, ELENA

2013 Entrevista con María Rierra (asistenta de investigación de la autora), Barcelona, 12 de junio.

RANDOM HOUSE

s.f. LLC: <http://www.randomhouse.biz/ourpublishers/>, consultada el 10 de agosto de 2014 .

RANDOM HOUSE MONDADORI

s.f. <http:/ / www.megustaleer.com.co/pagina/1/ quienes-somos / >, consultada el 10 de agosto de 2014.

Rodríguez Marcos, Javier

2011 "Santillana, un libro de medio siglo", El País, 18 de enero, en <http: / / elpais. com/diario / 2011 / 01 / 18 / cultura / 1295305207_850215.html\# despiece1>, consultada el 10 de agosto de 2014.

RUIZ, EZEQUIEL

2011 “Traducción de Dany Laferrière", comunicación vía correo electrónico, 28 de junio.

RuIZ, MARi Jose [antigua responsable de Relaciones Públicas de Txalaparta]

2011 Entrevista electrónica con la autora, 17 de noviembre.

2010 "Nikolski", comunicación vía correo electrónico, 5 de octubre.

SEIX BARRAL

2013 "Puta", comunicación vía correo electrónico, 23 de julio.

WARMUZIŃSKA-ROGÓŻ, JOANNA

2009 "La Richesse des sens dans Comment faire l'amour avec un nègre sans se fatiguer de Dany Laferrière dans la perspective traductologique", Synergies Pologne, vol. 6, pp. 203-213. 